\title{
Design and Gamma-Scintigraphic Evaluation of a Floating and Pulsatile Drug Delivery System Based on an Impermeable Cylinder
}

\author{
Hao Zou, ${ }^{a}$ Xuetao JiAnG, ${ }^{a}$ Lingshan Kong, ${ }^{b}$ and Shen GAO ${ }^{*}, a$ \\ ${ }^{a}$ Department of Pharmaceutics, School of Pharmacy, Second Military Medical University; No. 325 Guohe Road, Shanghai \\ 200433, P.R. China: and ${ }^{b}$ Department of Nuclear Medicine, Changhai Hospital of Second Military Medical University; \\ Shanghai 200433, P.R. China. Received November 21, 2006; accepted January 22, 2007
}

\begin{abstract}
A blend of floating and pulsatile principles of drug delivery system seems to present the advantage that a drug can be released in the upper GI tract after a definite time period of no drug release. The objective of this study was to develop and evaluate a floating and pulsatile drug delivery system based on an impermeable cylinder. Pulsatile capsule was prepared by sealing the drug tablet and the buoyant material filler inside the impermeable capsule body with erodible plug. The drug delivery system showed typical floating and pulsatile release profile with a lag time followed by a rapid release phase. The lag time prior to the pulsatile drug release correlated well with the erosion properties of plugs and the composition of the plug could be controlled by the weight of the plug. The buoyancy of the whole system depended on the bulk density of the dosage form. Gamma-scintigraphic evaluation in humans was used to establish methodology capable of showing the subsequent in vivo performance of the floating and pulsatile release capsule. Developed formulations showed instantaneous floating with no drug release during the lag time followed by a pulse drug release. From the gamma-scintigraphic results, the pulsatile release capsule we prepared could achieve a rapid release after lag time in vivo, which was longer than that in vitro. The scintigraphic evaluation could confirm qualitatively that the system with in vitro lag time of $4.0 \mathrm{~h}$ provided, with relatively high reproducibility, a pulsatile release occurred around $5.0 \mathrm{~h}$ after administration.
\end{abstract}

Key words pulsatile release system; floating dosage form; erosion plug; lag time; verapamil hydrochloride

Using current release technology, it is possible for many drugs oral delivery for a pulsed or pulsatile release, which is defined as the rapid and transient release of a certain amount of molecules within a short time-period immediately after a predetermined off-release period. ${ }^{1)}$ Such novel drug delivery has been attempted for: (i) chronopharmacotherapy of diseases which show circadian rhythms in their pathophysiology ${ }^{2}$; (ii) avoiding degradation of active ingredients in upper GI tract, e.g. proteins and peptides ${ }^{3)}$; (iii) for time programmed administration of hormones and many drugs such as isosorbide dinitrate, respectively to avoid suppression of normal secretion of hormones in body that can be hampered by constant release of hormone from administered dosage form and development of resistance ${ }^{4-9)}$; (iv) avoiding pharmacokinetic drug-drug interactions between concomitantly administered drugs. ${ }^{10)}$

Verapamil hydrochloride (Ver) was chosen as model drug, for it is a potent calcium-channel blocker and has been effective for preventing the time-related occurrence of ischemic. ${ }^{11)}$ Verapamil $\mathrm{HCl}$ has a distinct $\mathrm{pH}$-dependent solubility in the $\mathrm{pH}$-range of the gastrointestinal tract. ${ }^{12}$ ) The following solubility values have been reported: $>150,2.71$ and $0.75 \mathrm{mg} / \mathrm{ml}$ at $\mathrm{pH} 1.2,6.8$ and 7.4 , respectively. ${ }^{13)}$ With conventional pulsatile release dosage forms, a possible decrease in the release rate when passing from the stomach into the intestine can result in in vivo variability and bioavailability problems. Thus can result in incomplete drug absorption from the pulsatile release system with the lag time more than the relatively brief gastric emptying time ${ }^{14}$ ) and may lead to diminished efficacy of the administered dose. Overall, these considerations have led to the development of oral pulsatile release dosage forms possessing gastric retention capabilities.

Floating-pulsatile concept was applied to increase the gastric residence of the dosage form having lag phase followed by a burst release. Over the last three decades, various ap-

proaches have been pursued to increase the retention of an oral dosage form in the stomach, including floating systems, swelling and expanding systems, bioadhesive systems, modified-shape systems, high-density systems, and other delayed gastric emptying devices. ${ }^{14-16)}$ The dosage forms with hydrodynamically balanced systems possessing gastric retention capabilities have a bulk density lower than gastric fluids and thus remain buoyant in the stomach without affecting the gastric emptying rate for a prolonged period of time.

The present study focused on development and evaluate of a multifunctional drug delivery system, which was designed as a floating-pulsatile drug delivery system. Such drug delivery system is developed from the pulsatile system described by Krögel and Bodmeier ${ }^{17,18)}$ (Fig. 1, case 1). The novel system consists of a drug tablet placed within an impermeable polymeric cylinder closed with an erodible drug-free plug and floating material filled at the bottom (Fig. 1, case 2). When in contact with the aqueous fluids, the erodible drugfree plug is responsible for a lag phase preceding the onset of release and the floating material filled at the bottom is re-

Case 1

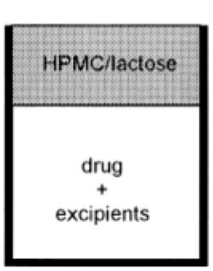

Fig. 1. Configurations of a Novel Drug Delivery Systems Based on an Impermeable Cylinder

Case 1, pulsatile system (drug-filled impermeable capsule half closed with an erodible drug-free plug). Case 2, floating and pulsatile system (drug-filled impermeable capsule half closed with an erodible drug-free plug and the floating material filled at the bottom). 


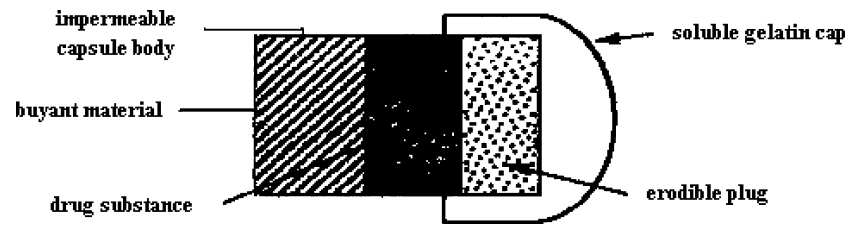

Fig. 2. Configuration of Floating and Pulsatile Drug Delivery Systems Based on an Impermeable Cylinder

sponsible for buoyancy properties of the formulation.

Up to now, few studies have been reported on the design of the floating-pulsatile release system and the in vivo performances of this system. The present study described an in vivo investigation in half-fed ( $4 \mathrm{~h}$ after dinner) healthy male subjects, in which the gastrointestinal transit of this floating-pulsatile drug delivery system is compared with that of a nonfloating system manufactured from identical material.

\section{Experimental}

Materials and Apparatus Hydroxypropyl methylcellulose (HPMC Methocel $^{\circledR}$ E5, E15, E50, Colorcon, Orpington, U.K.), Ethylcellulose (EC, Ethoce $^{\circledR}$ 45P, Colorcon, Orpington, U.K.), hard gelatin capsules, size 0, (Huangshan, Anhui, China), Verapamil hydrochloride (Tianjin Central Pharmaceutical Factory, Tianjin, China); Crospovidone (Kollidon ${ }^{\circledR}$ CL, BASF, Ludwigshafen, Germany), Polyvinyl pyrrolidone (Kollidon ${ }^{\circledR}$ 30, BASF, Ludwigshafen, Germany), Hydrogenated Castor Oil (HCO, Tongliao, Neimenggu, China), $\alpha$-Lactose (Chemistry Reagents, Shanghai, China), magnesium stearate (MS, Shanghai Chemistry Reagents Separately Packed, China), All other reagents were of analytical grade and were used without further purification. Technetium $99 \mathrm{~m}\left(\mathrm{TcO}^{4-}\right)$ was obtained from Changhai hospital, Shanghai, China. In vitro release for the floating and pulsatile release tablet was evaluated in $900 \mathrm{ml}$ of dissolution fluid at $37^{\circ} \mathrm{C}$ using the rotation basket dissolution test at a rotation rate $100 \mathrm{r} / \mathrm{min}$ (six replicates). Drug concentrations in the dissolution medium were determined spectrophotometrically (UV-265 FW, Shimadazu, Japan) and assayed at $229 \mathrm{~nm}$. In vivo images were obtained with an Ohio Nuclear Sigma 410 gamma camera (Packard Instrument Company).

Preparation of Impermeable Capsule Body A capsule body (separated from the caps) was made of EC (Ethocel ${ }^{\mathbb{B}} 45 \mathrm{P}$ ). To make the impermeable capsule body, $2.2 \mathrm{~g}$ of EC was dissolved in $20 \mathrm{ml}$ of the mixture of dichloromethane and castor oil with stirring. To the body of size 0 gelatin capsule, about $1 \mathrm{ml}$ of the prepared EC solution was fulfilled. Thereafter, the solvent was evaporated overnight at $6{ }^{\circ} \mathrm{C}$ in a refrigerator. After the gelatin layer was dissolved in water, the impermeable capsule body (the top inner diameter $6.02 \pm 0.04 \mathrm{~mm}$, length $16.46 \pm 0.07 \mathrm{~mm}$, thickness of the wall $0.170 \pm 0.010 \mathrm{~mm}$ ) was obtained.

Preparation of the Drug Tablet The drug tablet contained verapamil hydrochloride $(40 \%, \mathrm{w} / \mathrm{w})$, crospovidone $(20 \%, \mathrm{w} / \mathrm{w})$ and $\alpha$-Lactose $(40 \%$, $\mathrm{w} / \mathrm{w})$. The drug was mixed with the excipients and then wetted with $5 \% \mathrm{PVP}$ ethanol solution. The wetted mass was forced through a 16-mesh screen. The granules obtained were dried in a circulating air oven at $55^{\circ} \mathrm{C}$ for $45 \mathrm{~min}$ and calibrated through the same screen. Magnesium stearate $(1 \%$, $\mathrm{w} / \mathrm{w})$ was added to granulate and mixed. Then the dried mass was compressed to tablets (hardness: $40-70 \mathrm{~N}$, weight $100 \mathrm{mg}$; the mean height $2.05 \mathrm{~mm}$ ) using $6 \mathrm{~mm}$ diameter single-punch using a conventional single punch press (TDP type; First Pharmacy Machine, Shanghai, China).

Preparation of the Erodible Plug The powder $(20 \%, \mathrm{w} / \mathrm{w}, \alpha$-Lactose, $80 \%$, w/w, HPMC, unless otherwise mentioned) was sieved through a $800-$ $\mathrm{mm}$ sieve and then blended for $15 \mathrm{~min}$ in a Turbula-mixer (21 W.A. Bachhofen Maschinenfabrik, Basel, Switzerland) followed by the addition of $1 \%$ $(\mathrm{w} / \mathrm{w})$ magnesium stearate and further blending for $5 \mathrm{~min}$. The plugs (diameter: $6.0 \mathrm{~mm}$; hardness: $40-70 \mathrm{~N}, 78 \mathrm{X}-3 \mathrm{C}$ hardness tester, Huanghai Pharmacy Machine, Shanghai, China; weight $150 \mathrm{mg}$; the mean height was $2.45 \mathrm{~mm}$ ) were prepared by direct compression with a single punch press.

Filling of Floating-Pulsatile Release Capsule The buoyant material (e.g. Hydrogenated Castor Oil) granules were sieved through 16-mesh screen followed by hand-filling the capsule body up to height $12 \mathrm{~mm}$ (fil weight: $200-250 \mathrm{mg}$, according to the bulk density of the buoyant material). Then the drug tablet was positioned by hand within the capsule body. Then the erodile plug (same diameter as the top inner diameter of capsule body) was placed into capsule body next to the drug tablet. The floating and pulsatile release capsules were assembled using the configuration in Fig. 2. In this study twenty capsules per batch were prepared by the present method.

Dissolution Test USP 26 type I dissolution apparatus was employed with a dissolution test apparatus (ZRS-8G type; Radio Equipment of Tianjing University, China). The medium was $900 \mathrm{ml}$ (V) dissolution medium at $37 \pm 0.5^{\circ} \mathrm{C}$ and the rotating speed was $100 \mathrm{rpm}$. At appropriate time intervals, $5 \mathrm{ml}$ of the solution was withdrawn, filtered, and assayed by a UV spectrophotometer (UV2000 type; Third Analysis Machine, Shanghai, China) at $229 \mathrm{~nm}$, while an equal volume of fresh dissolution medium added into the apparatus. In certain studies, the dissolution medium $(0.1 \mathrm{M} \mathrm{HCl}$ and $\mathrm{pH} 7.4$ phosphate buffered saline; PBS) and stirring rate $(50$ and $100 \mathrm{rpm})$ were varied. In vitro lag time was calculated by extrapolation on the $x$-axis of the initial steep portion of each individual release curve.

Floating Behavior of Capsule The in vitro floating behavior of capsules was studied by placing them in $900 \mathrm{ml}$ containers $\left(37^{\circ} \mathrm{C}, 100 \mathrm{rpm}\right.$, $n=6$ ). The floating and pulsatile release capsule (FPRC) was always floating on the surface. The floating ability of FPRC was determined by visual observation.

Gamma-Scintigraphic Study Technitium- $99 \mathrm{~m}\left({ }^{99 \mathrm{~m}} \mathrm{TcO}^{4-}\right)$ is the radioisotope of choice for nuclear medicine imaging studies. It has a short half-life of $6.03 \mathrm{~h}$ and is easy and inexpensive to produce. ${ }^{99 \mathrm{~m}} \mathrm{Tc}$ is eluted as pertechnetate $\left({ }^{99 \mathrm{~m}} \mathrm{TcO}^{4-}\right)$, with sodium chloride $0.9 \%$ from a molybdenum99 generator. ${ }^{19,20)}$ The drug tablet containing ${ }^{99 \mathrm{~m}} \mathrm{Tc}-\mathrm{DTPA}(1.5 \mathrm{MBq})(\mathrm{ab}-$ sorbed on dried sodium chloride) was prepared as described above. Quantity weighing $52 \mathrm{mg}$ was taken and compressed individually into tablets using $6 \mathrm{~mm}$ flat plain punches on a single-punch tablet machine. Each tablet contained $1.5 \mathrm{MBq}$ of ${ }^{99 \mathrm{~m}} \mathrm{TcO}^{4-}$.

The radio-labeled floating and pulsatile release capsule (FPRC) was prepared by the buoyant material (Hydrogenated Castor Oil) granules, the drug tablet containing ${ }^{99 \mathrm{~m}} \mathrm{Tc}-\mathrm{DTPA}$ and the erodile plug $(100-\mathrm{mg}, 30 \%$, w/w, $\alpha$ Lactose, 70\%, w/w, HPMC E5).

The radio-labeled non-floating and non-pulsatile release capsule (NRC) was prepared by $\alpha$-Lactose as the substitute of the buoyant material, the drug tablet containing ${ }^{99 \mathrm{~m}} \mathrm{Tc}-\mathrm{DTPA}$ and the non-erodile plug. Instead of HPMC, EC was used as main excipients of the non-erodile plug of NRC.

Six healthy males with ranging ages $(28-38)$, weights $(63-75 \mathrm{~kg})$ and heights $(165-186 \mathrm{~cm})$ were selected and they provided written consent to take part in the study in Changhai hospital of Second Military Medical University. No volunteer were taking any regular medication or had a history of gastrointestinal disorders. Those volunteers who were smokers abstained during the study. The protocol was approved by the local Ethics Committee.

Two capsules (one FPRC and one NRC) were administered to each volunteer, $4 \mathrm{~h}$ after dinner and then remained supine $8 \mathrm{~h}$ following the dose, with $200 \mathrm{ml}$ of water containing ${ }^{99 \mathrm{~m}} \mathrm{Tc}$-DTPA, to outline the gastrointestinal tract. Subjects were allowed to lie on their backs or on their left side for the duration of the study. Through the images taken at 30-min intervals by a gammacamera the gastrointestinal transit of the dosage forms was followed and the site and time of their break-up were assessed.

In vivo images were obtained with an Ohio Nuclear Sigma 410 gamma camera (Packard Instrument Company), which was fitted with a $40 \mathrm{~cm}$ parallel hole collimator. Data were collected on magnetic disk for future analysis using MAPS 2000 software.

The gamma scintigraphic images were assessed by visual examination. The time to the onset of gastric emptying was determined as the time that showed hotspots of radioactivity leaving the stomach and entering the small intestine. The time of FPRC breaking-up, as determined by spreading of radiolabel in the GI tract contents, was determined by examination of the scintiscans.

\section{Result and Discussion}

For the development of floating and pulsatile systems based on the impermeable capsule body, several preliminary studies were necessary to identify the capsule body and components of the erodible plug resulting in the desired system properties.

First, properties of the impermeable capsule body (type of polymer films, type and concentration of the plasticizer) were investigated. The impermeable capsule body was consisted of EC (Ethocel ${ }^{\circledR} 45 \mathrm{P}$ ) and plasticizers. The influence of two commonly used plasticizers, castor oil (CO) or dibutyl seba- 
Table 1. Influence of Different Plasticizer on Mechanical Properties of the Impermeable Capsule Body

\begin{tabular}{|c|c|c|c|c|c|}
\hline \multirow[b]{2}{*}{ Formulation } & \multicolumn{3}{|c|}{ Composition } & \multirow[b]{2}{*}{ Hardness } & \multirow{2}{*}{$\begin{array}{l}\text { Thickness of the } \\
\text { impermeable } \\
\text { capsule body }\end{array}$} \\
\hline & $\begin{array}{c}\mathrm{EC} \\
(\mathrm{w} / \mathrm{v})\end{array}$ & $\begin{array}{l}\text { Castor Oil } \\
(\mathrm{w} / \mathrm{v})\end{array}$ & $\begin{array}{c}\text { Dibutyl sebacate } \\
\qquad(\mathrm{w} / \mathrm{v})\end{array}$ & & \\
\hline 1 & $11 \%$ & $2 \%$ & & Hardness & Thinness \\
\hline 2 & $11 \%$ & $3 \%$ & & Fitness & Fitness \\
\hline 3 & $11 \%$ & $4 \%$ & & Fitness & Thickness \\
\hline 4 & $11 \%$ & & $5 \%$ & Softness & Fitness \\
\hline 5 & $11 \%$ & & $10 \%$ & Softness & Fitness \\
\hline 6 & $11 \%$ & & $30 \%$ & Softness & Thickness \\
\hline
\end{tabular}

cate (DBS), on mechanical properties of the impermeable capsule body was investigated. To the body of size 0 gelatin capsule, $1 \mathrm{ml}$ of the prepared EC solution $(11 \%$, w/v) was fulfilled. The content of plasticizers in the solution were varied to obtain an optimized impermeable capsule body. The results of studies (Table 1) showed that the kind of plasticizers influence hardness and thickness of the impermeable capsule body. Concerning the mechanical properties, the polymer films of the impermeable capsule body should be flexible and puncture strength enough to place the erodile plug and the drug tablet into capsule body. A tight fit between the plug and the impermeable capsule shell was very important to prevent water penetration to the capsule content and drug release prior to complete erosion of plug materials. Ethyl cellulose was suitable candidates for the floating delivery system based on the impermeable capsule body. The capsule body prepared by ethyl cellulose solution (plasticized with $5 \%, 10 \%, 30 \%$, w/v, DBS) was too soft. Increasing the concentration of castor oil in EC solution from 2 to $4 \%$ (w/v) decreased the hardness and increased the thickness of the impermeable capsule shell. The optimized impermeable capsule body prepared by $11 \%(\mathrm{w} / \mathrm{v})$ EC and 3\% (w/v) castor oil.

Besides the impermeable capsule body, the erodible plug had a major impact on the performance of the delivery system. The pulsatile system consisted of an impermeable capsule half-filled with the drug tablet and closed with a drugfree erodible matrix tablet, forming the plug. After a predetermined lag time of no release, governed by the erosion/dissolution of the erodible plug, the content was released in a pulsatile fashion. ${ }^{17,18)}$

In order to identify proper plug material, the lag times of the floating and pulsatile release capsule with different plug materials were investigated (Fig. 3). Ideally, the plug should erode only from the surface exposed to the release medium. The water-soluble polymers hydroxypropyl methylcellulose (HPMC), Povidone (PVP) appeared attractive as erodible plug material because of their frequent use in pulsatile system. The plug prepared using Povidone (including PVP-k30, k90) could achieved lag time no more than $2 \mathrm{~h}$. With an aim to obtain a burst release of the drug after $4 \mathrm{~h}$, HPMC was chosen as the plug material because of longer lag times. Three different viscosity grades of HPMC (Methocel ${ }^{\circledR}$ E5, E15, E50) were evaluated (Fig. 4). The higher viscosity grade HPMC resulted in longer lag times.

The lag time prior to the drug release depended on the rate of erosion of the plug, which could be controlled by factors such as the composition ( $\alpha$-Lactose to erodible material ratio) or the weight (thickness) of the erodible plug (Fig. 5).

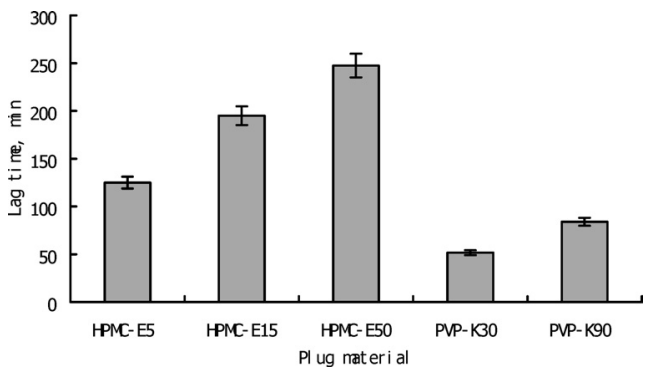

Fig. 3. Influence of Different Plug Materials in the Erodible Plug on the Lag Time of the Drug Pulsatile Release Capsule (the Erodile Plug, $\alpha$-Lactose $80 \%$, w/w; Plug Material, $20 \%$, w/w)
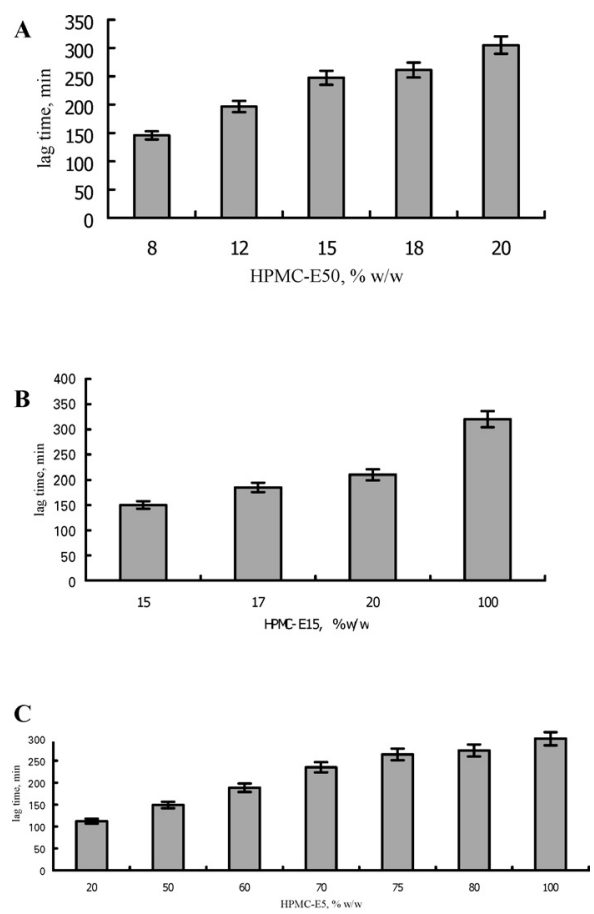

Fig. 4. Influence of the HPMC Content in the Erodible Plug on the Lag Time of the Drug Pulsatile Release Capsule

(A) HPMC E50; (B) HPMC E15; (C) HPMC E5.

The lag time could be well controlled by the composition and weight of the erodible plug, it increased with increasing plug weight and erodible material content in the plug.

When comparing three different viscosity grades of HPMC (Methocel ${ }^{\mathbb{R}}$ E5, E15, E50) within this study it was found that pulsatile capsules prepared using Methocel ${ }^{\mathbb{B}} \mathrm{E} 5$ required a higher HPMC percent in the erodible plug com- 
pared to Methocel ${ }^{\circledR}$ E15, E50 in order to achieve the same lag time. Further the system with Methocel ${ }^{\circledR}$ E5 was less sensitive to the amount of HPMC in the erodible plug, which might be important from a manufacturing point of view. This could be very advantageous, because a deviation of the amount of Methocel ${ }^{\circledR}$ E5 in the plug would result in only relatively small changes in lag time and consequently reproducible drug release profiles, with rapid and complete drug release. Methocel ${ }^{\mathbb{R}}$ E5 is used as plug material for the preparation of the erodible plug as is described further down. The 100 -mg erodible plug Methocel ${ }^{\circledR}$ E5 and $\alpha$-Lactose $(7: 3$, $\mathrm{w} / \mathrm{w})$ could be successfully applied to obtain a lag time of $4 \mathrm{~h}$ (Fig. 4C).

Floating behavior of the system with the different floating material was also investigated (Table 2). When the system with Hydrogenated Castor Oil or Hexadecanol was immersed in solution, it was found to floating within $12 \mathrm{~h}$, thus, showing floating ability depending on the total amount of the buoyant materials. The FPRC were always floating on the surface of the solution. The system with $\alpha$-Lactose was sunk at once in the solution and was not found to floating anytime. So 200-mg Hydrogenated Castor Oil as floating material was necessary and enough. The total weight of floating-pulsatile

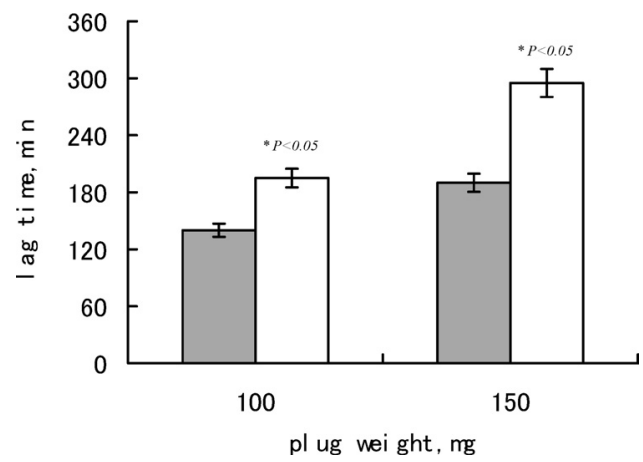

Fig. 5. Influence of the Erodible Plug Weight on the Lag Time of the Floating and Pulsatile Release Capsule

—, $50 \%$ HPMC E-5; $\square, 60 \%$ HPMC E-5. release capsule with Hydrogenated Castor Oil was $450 \mathrm{mg}$. The bulk density of the capsules calculated from the total volume (about $0.65 \mathrm{ml}$ ) was about $0.69 \mathrm{~g} / \mathrm{ml}$. Thus, the FPRC can maintain an overall specific gravity lower than that of gastric contents (reported as $1.004-1.01 \mathrm{~g} / \mathrm{ml}$ ).

USP 26 type I dissolution apparatus was employed with a dissolution test apparatus. The medium was $900 \mathrm{ml}(\mathrm{V})$ dissolution medium at $37 \pm 0.5{ }^{\circ} \mathrm{C}$ and the rotating speed was $100 \mathrm{rpm}$. The release profile revealed pulsatile characteristics. After a lag time with no drug release, the drug was released within a relatively short time period. The effect of the rotating speed and dissolution medium would be expected to exert an influence on erosion from HPMC-based surfaces during dissolution studies and this was shown to be the case (Figs. 6, 7). Result (Fig. 6) showed the influence of rotation speed on the lag time of the pulsatile release in distilled water, where longer lag time was observed at $50 \mathrm{rpm}$ than $100 \mathrm{rpm}$. Whether such effects would have an influence on in-vivo performance remained to be determined and was subject of an ongoing investigation. Simulated gastric fluid without enzymes (SGF), simulated intestinal fluid, without enzymes (SIF), distilled water was used as dissolution medium and dissolutions were performed for $6 \mathrm{~h}$. The lag time of the pulsatile system closed with the plug with 70\% HPMC-E5 in three dissolution media (Fig. 7) were $(230.2 \pm 25.0) \mathrm{min}$, $(239 \pm 23.1) \mathrm{min},(284 \pm 35.6) \mathrm{min}$. There were no significant different.

The floating and pulsatile release capsule for in vivo study was manufactured as described above and 200-mg hydrogenated castor oil was used as the buoyant material combined with the drug tablet containing 40-mg verapamil hydrochloride and the 100-mg erodible plug with HPMC-E5 and $\alpha$-Lactose $(7: 3, \mathrm{w} / \mathrm{w})$.

Six healthy males took part in the gamma scintigraphy study. Figure 8 showed the series of gamma scintigraphic images that were obtained for volunteer 1 when the FPRC and NRC were swallowed with $200 \mathrm{ml}$ of water containing ${ }^{99 \mathrm{~m}} \mathrm{Tc}-\mathrm{DTPA}$, to outline the gastrointestinal tract. Within the series, the position of the two capsules in the stomach of the

Table 2. Influence of the Kind and Weight of Floating Material on the Floating Ability of the Floating and Pulsatile Capsule

\begin{tabular}{clccc}
\hline \hline Formulation & Floating material & Weight $(\mathrm{mg})$ & Floating ability & Lag time \\
\hline 1 & Hydrogenated Castor Oil & 200 & Floating & $186 \mathrm{~min}$ \\
2 & Hexadecanol & 220 & Floating & $181 \mathrm{~min}$ \\
3 & $\alpha$-Lactose & 350 & Sank & $170 \mathrm{~min}$ \\
\hline
\end{tabular}

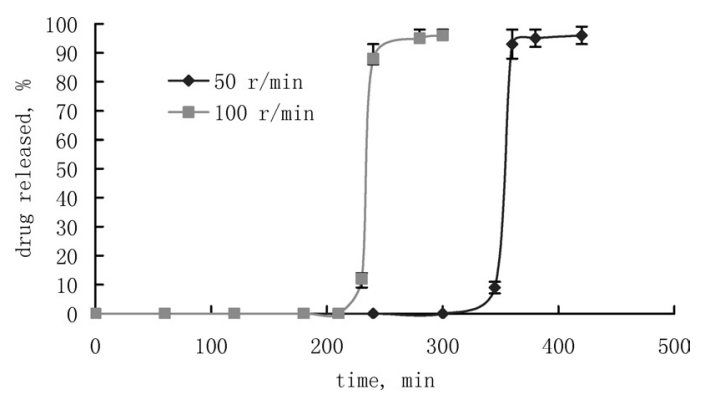

Fig. 6. Influence of Rotation Rate on the Drug Pulsatile Release in Distilled Water Using USP 26 Type I Dissolution Method (the Erodile Plug, $\alpha$ Lactose 30\%, w/w; HPMC-E5 70\%, w/w)

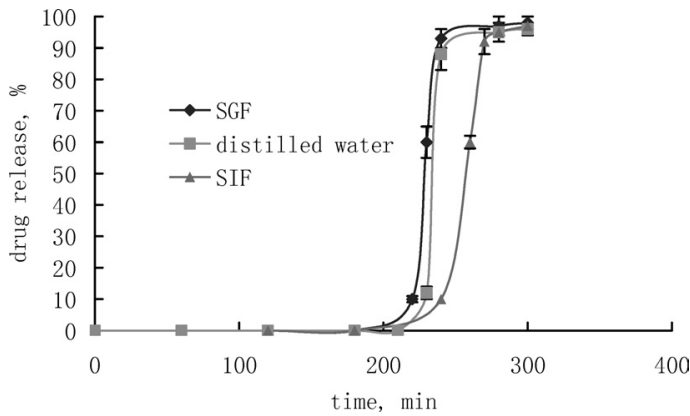

Fig. 7. Influence of Dissolution Medium on the Drug Pulsatile Release Using USP 26 Type I Dissolution Method by Rotation Rate $100 \mathrm{rpm}$ (the Erodile Lug, $\alpha$-Lactose 30\%, w/w; HPMC-E5 70\%, w/w) 


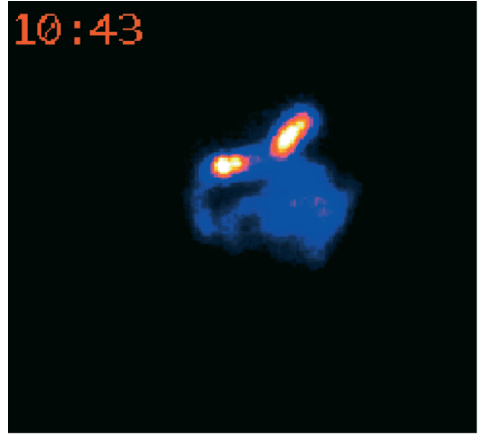

a

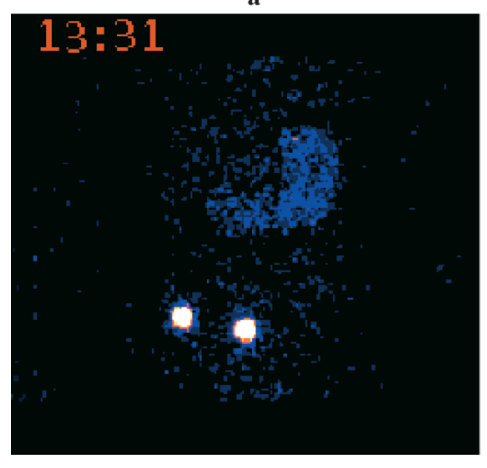

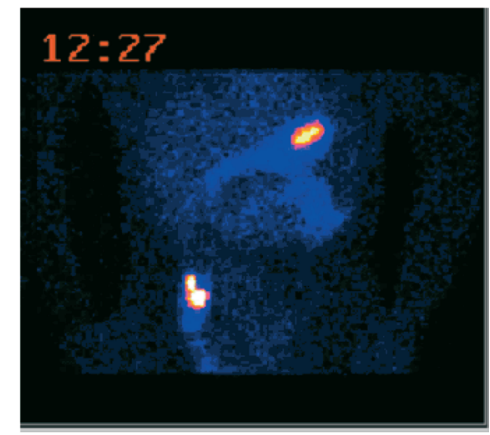

b

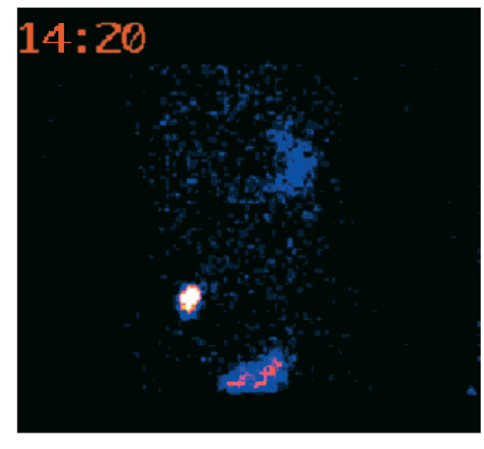

d

Fig. 8. Gamma Scintigraphic Images Showing the Movement of FPRC and NRC for Volunteer 1 at Selected Time-Points When the Two Tablets Were Administered with $200 \mathrm{ml}$ of Water

(a) Forty minutes showing FPRC and NRC with the intact tracer-containing core somewhere in the stomach, (b) $2.5 \mathrm{~h}$ showing NRC had left the stomach, FPRC remained in the stomach, (c) $3.5 \mathrm{~h}$ showing both of FPRC and NRC were found to have left the stomach, (d) $4.5 \mathrm{~h}$ showing the disintegration of the tracer-containing core from the FPRC with the spread in the small intestine.

volunteer and the passage through to the intestine could clearly be seen. The red areas, indicating greater radioactivity, depicted the FPRC or NRC. The images and anatomical visualizations shown in Fig. 8 were representative of all the volunteers.

Figure 8 showed distinct areas of radioactivity with both stomach and intestinal areas highlighted. Gastric emptying was deemed complete when either two successive images of minimal radioactivity were collected or by noting the last time that two units were seen in the stomach and the next frame that clearly showed that one or both units had left the stomach. ${ }^{21)}$ The window of time in all cases between the two points was $30 \mathrm{~min}$, and therefore, the measure of gastric emptying was complete within a time error of $\pm 15 \mathrm{~min}$. The gastric emptying times of FPRC or NRC for volunteer 1 are reflected by Figs. $8 \mathrm{~b}$ and $\mathrm{c}$ for the current study.

Pulsatile release time of FPRC was defined as the time at which all the radio labeled tablet dissipated in the GI tract and no signs of a distinct "core" remained. Scintigraphic images from the study show that when the unit released in the stomach there was a marked increase in dispersion of the marker. ${ }^{22)}$ Through the images taken at 30-min intervals by a gamma-camera the gastrointestinal transit of the dosage forms was followed and the site and time of their break-up were assessed. The pulsatile release time of FPRC for volunteer 1 were reflected by Fig. $8 \mathrm{~d}$ for the current study.

In all studies the two capsules (FPRC and NRC) remained as two distinct the signs with a distinct "core" whilst in the gastrointestinal tract before the pulsatile release occurred. But once the pulsatile release of FPRC occurring, the entire radio-labeled tablet dissipated in the GI tract. Such observa- tions were expected, as NRT, sealed with EC instead of HPMC-E5, could not release the intact tracer within the core at any time and the sign of a distinct "core" remained. So the capsule remaining in the stomach and pulsatile-releasing the tracer was FPRC, the other was NRC.

A summary of the results showing the onset times to gastric emptying and the pulsatile release time that were obtained for the six volunteers taking part in the study is shown in Table 3.

Overall, Table 3 showed that the floating and pulsatile release capsule (FPRC) used in the study could be retained in the stomach for extended periods in the half-fed state $(4 \mathrm{~h}$ after dinner). The gastric retention of the FPRC tablet was observed in six volunteers that took part in the study. When compared with the time to onset of emptying of NRC, the gastric residence time of FPRC was found to increase in excess of $3.5 \mathrm{~h}$. In addition to the times recorded for the onset of gastric emptying, the pulsatile release time from the FPRC was also noted. The analysis of gamma scintigraphic images for the volunteers showed that in vivo lag time values ( $5.08 \pm 0.53 \mathrm{~h}$ on average) of FPRC were found to be the relatively low variability and be longer than the corresponding in vitro lag time $(239 \pm 23.1) \mathrm{min}$.

These results also showed that the anatomical position of disintegration of FPRC cannot control at only stomach (two at stomach, four at small intestine). Small intestine as the main disintegration position means the capsules were excluded to small intestine, i.e. floating is not enough in vivo. But in vitro study, the capsules was found to floating within $12 \mathrm{~h}$. Providing FPRC remained buoyant in vivo, the biological factor of the subject can be the rate-limiting step in the 
Table 3. Gastric Retention Time and Pusatile Release Time of FPRC ${ }^{b)}$ and NRC ${ }^{a)}$

\begin{tabular}{|c|c|c|c|c|c|}
\hline \multirow{2}{*}{ Subjects } & \multicolumn{2}{|c|}{ Gastric retention time (h) } & \multicolumn{2}{|c|}{ Pulsatile release time (h) } & \multirow{2}{*}{$\begin{array}{c}\text { Anatomical position of disintegration } \\
\text { FPRC }\end{array}$} \\
\hline & NRC & FPRC & NRC & FPRC & \\
\hline 1 & 1.0 & 3.5 & $-^{c)}$ & 4.5 & Small intestine \\
\hline 2 & 1.0 & $>5.0$ & - & 5.0 & Stomach \\
\hline 3 & 0.5 & 3.5 & - & 5.5 & Small intestine \\
\hline 4 & 1.5 & 4.0 & - & 5.0 & Small intestine \\
\hline 5 & 1.0 & $>4.5$ & - & 4.5 & Stomach \\
\hline 6 & 1.5 & 3.0 & - & 6.0 & Small intestine \\
\hline Mean \pm S.D. & $1.08 \pm 0.34$ & & & $5.08 \pm 0.53$ & \\
\hline
\end{tabular}

a) The radio-labeled non-floating and non-pulsatile release capsule. b) The radio-labeled floating and pulsatile release capsule. c) Not occured.

gastric retention time of FPRC. One of the disadvantages of the floating system may be that FPRC require a sufficiently high level of fluids in the stomach for the drug delivery buoy to float therein and to work efficiently. This limitation may be overcome by coating the dosage form with bioadhesive polymers, thereby enabling the system to adhere to the mucous lining of the stomach wall.

\section{Conclusion}

A new type of floating-pulsatile drug delivery system based on the 100-mg erodible plug with HPMC-E5 and $\alpha$ Lactose $(7: 3, \mathrm{w} / \mathrm{w})$ as controller of the pulsatile release and 200-mg hydrogenated castor oil as the buoyant material has been developed. Developed formulations showed instantaneous floating with no drug release during the lag time followed by a pulsatile drug release. From the results obtained we highlighted the following important points: the pulsatile release capsule we prepared could achieve a rapid release after lag time in vivo, which was longer than that in vitro. The scintigraphic evaluation could only confirm qualitatively that the system with in vitro lag time of $4.0 \mathrm{~h}$ provided, with relatively high reproducibility, a pulsatile release around $5.0 \mathrm{~h}$ after administration. The developed system offers a novel technique for pulsatile release of drugs in upper part of small intestine. Such work can be further extended using various excipients for variety of drugs suitable for chronopharmaceutical drug delivery.

Acknowledgment Authors wish to acknowledge the National Natural Science Foundation of China (NSFC) (No. 30070898) and the Shanghai Science and Technology Commission for financial support.

\section{References}

1) Kikuchi A., Okano T., Adv. Drug Del. Rev., 54, 53-77 (2002).
2) Sawada T., Kondo H., Nakashima H., Sako K., Hayashi M., Int. J. Pharm., 280, 103-111 (2004).

3) Rubinstein A., Tirosh B., Baluom M., Nassar T., David A., Radai R., Gliko-Kabir I., Friedman M., J. Control. Rel., 46, 59-73 (1997).

4) Parker J. O., Fung H. L., Rugginello D., Stone J. A., Circulation, 68, 1074-1080 (1983).

5) Goldenheim P. D., Conrad E. A., Schein L. K., Chronobiol. Int., 4, 397-408 (1987)

6) Flaherty J. T., Drugs, 37, 523-550 (1989).

7) Jimoh A. G., Wise D. L., Gresser J. D., Trantolo D. J., J. Control. Rel., 34, 87-95 (1995).

8) Charloux A., Gronfier C., Lonsdorfer-Wolf E., Piquard F., Brandenberger G., Am. J. Physiol., 276, E43-E49 (1999).

9) Terasawa E., Keen K. L., Mogi K., Claude P., Endocrinology, 140, 1432-1441 (1999).

10) Sawada T., Sako K., Yoshihara K., Nakamura K., Yokohama S., Hayashi M., J. Pharm. Sci., 92, 790-797 (2003).

11) McTavish D., Sorkin E. M., Drugs, 38, 19-76 (1989).

12) Klausner E. A., Lavy E., Friedman M., Hoffma A., J. Control. Rel., 90, $143-162$ (2003).

13) Streubel A., Siepmann J., Dashevsky A., Bodmeier R., J. Control. Rel., 67, 101-110 (2000).

14) Singh B. N., Kim K. H., J. Control. Rel., 63, 235-259 (2000).

15) Whitehead L., Fell J. T., Collett J. H., Sharma H. L., Smith A.-M., J. Control. Rel., 55, 3-12 (1998).

16) Rahman Z., Ali M., Khar R., Acta Pharm., 56, 49-57 (2006).

17) Krögel I., Bodmeier R., J. Control. Rel., 61, 43-50 (1999).

18) Krögel I., Bodmeier R., Pharm. Res., 5, 474- 480 (1998).

19) Stops F., Fell J. T., Collett J. H., Martini L. G., Sharma H. L., Smith A.-M., Int. J. Pharm., 308, 8-13 (2005).

20) Sinha V. R., Mittal B. R., Kumria R., Int. J. Pharm., 289, 79-85 (2005).

21) Sato Y., Kawashima Y., Takeuchi H., Yamamoto H., Fujibayashi Y., J. Control. Rel., 98, 75-85 (2004).

22) Stevens H. N. E., Wilson C. G., Welling P. G., Bakhshaee M., Binns J. S., Perkins A. C., Frier M., Blackshaw E. P., Frame M. W., Nichols D. J., Humphrey M. J., Wicks S. R., Int. J. Pharm., 236, 27-34 (2002). 